Cumhuriyet International Journal of Education-CIJE

e-ISSN: 2147-1606

Vol 5 (1), 2016, 29 - 52

\title{
Administration and Supervision of the Educational Activities of Public Benefit Associaitions in Turkey (A Qualitative Analysis Based on the Legal Documents)
}

\author{
Erdal TOPRAKÇI, Aysun AKÇAY
}

\section{Summary}

The purpose of this study was to determine the scientific eligibility of the education activities of the Turkish associations operating in the public interest in terms of the educational administration and supervision processes on the basis of their legal documents. To fulfill this purpose the charters of the associations were examined according to the administration and supervision processes. In this study the document analysis which is one of the qualitative research designs was used. The data resources of the study were composed of the up to date internet based associations' charters and Law of Associations. Content analysis is used for the data. Regarding the purpose of the research, analysis units such as word, sentence, paragraph and content were utilized.

The frequencies of the statements about the educational administration and supervision processes of 94 associations were determined. According to the results of the research, 776 statements related to the administration and 5 statements related to the supervision processes identified from the charters and Law of Associations respectively. 22 as the largest number of the statements about the management and supervision of educational activities belonged to the Green Crescent Association and this is followed by 21 statements included in the charter of Six Dots Association of Visually Impaired Individuals. The smallest number of statements were included in the charters of Association for the Physically Disabled as 2 and Aid Association for the Darülaceze as 1 statement.

The function of planning with 246 statements was the first among the other management functions and this was followed by evaluation with 145 statements, influencing with 142, communication with 109 statements, organizing with 52 statements and decision making which was the lest mentioned function with 14 statements. The examination of the associations' charters revealed that the education activities and their management were performed along with other activities of the associations. In addition to that, it was seen that an internal unit for these activities was not formed. Only, divisions as sub-units of the board of directors were established to raise the educational awareness. Here, it has been noticed that the associations developed their educational activities in line with their establishment purposes. To answer another sub-problem of the research the educational supervision concepts namely, determining what is to be supervised, the preparation for the supervision, the establishment of standards, supervision-related data collection, comparison of the supervision data with the standards and reporting were taken into account. Activities encapsulating these steps and processes were sought for in the raw data obtained from the associations' charters. Activities making up the supervision process were unified under the concept of educational supervision process and a frequency table was constructed. In this way, it was tried to put forth the frequencies of the statements about the educational supervision steps and processes mentioned. It is concluded that the associations did not have any distinct supervision activities for the educational administration and supervision processes. Thus, supervision is thought to be conducted within the other administrative activities of the associations. For all the associations a general system of supervision based on an internal supervision framework was observed. In addition to this, there were not any specific supervision principles concerning the each distinct function of the associations. 
As a result, it is identified that the management and the supervision of the educational activities of the associations were not carried out on a scientific basis and moreover these activities are not supervised scientifically by Ministry of National Education or any other institutions. In accordance with these results it can be suggested that the educational activities of the associations and the contents of their charters should benefit from the disciplines of Educational Administration and Educational Supervision. In addition to these, the educational activities of the associations should be supervised by Ministry of National Education in order to formalize the informal education as much as possible. It can be suggested that following researches concerning this subject may include the in-depth study of the associations' educational activities via the interviews and documents other than the charters. Moreover, the educational activities of the associations can be observed and results can be evaluated based on the use level of the principles of educational administration and supervision. Also this study can be replicated with examining the charters of the other associations. 